\title{
Creation of the probiotic consortium on the base of strains of Bifidobacterium spp.
}

\author{
Kozhakhmetov S. S., * Oralbayeva S. S., Kushugulova A. R., Almagambetov K. Kh., Abzhalelov A. B. and \\ Ramankulov E. M.
}

Department of Genetics and Biochemistry, Republican Collection of Microorganisms NCB RK, Astana, Valikhanova str. 43, Republic of Kazakhstan.

E-mail: Igene@biocenter.kz

Received 10 October 2008; received in revised form 9 January 2009; accepted 4 March 2009

\begin{abstract}
Nowadays, a widespread circulation of disbiotic conditions among the population of all ages in Kazakhstan requires an active development in industry for both preparations and products with probiotic properties. The gained bacterial isolates, Bifidobacterium adolescentis 180, B. breve 204, B. breve 584 and B. breve 587 were used in our researches and screening showed they possess high probiotic properties. The consortium possesses strong antimicrobial activity to pathogenic and potentially-pathogenic microflora, insulated during disbacteriosis, as well as from vagina and urea. They are able to produce vitamin $B_{12}$ and also have antimutagenic activity. As a result, the consortium on the base of strains of Bifidobacterium spp. was received, possessing the following advantages: contains live mass of microbial, antagonistically active strains $B$. breve and $B$. adolescentis; contains more than $10^{9}$ alive Bifidobacteria; does not contain plasmids, which means that it could not be a carrier of antibiotic stability for Gram-positive receptive pathogenic and potentially-pathogenic microflora.
\end{abstract}

Keywords: Bifidobacteria, normal microflora, disbacteriosis, probiotic consortium, bifidogenic effect

\section{INTRODUCTION}

Nowadays, a widespread circulation of disbiotic conditions among the population of all ages in Kazakhstan requires an active development of industry of both preparations and products with probiotic properties (Dunne et al., 1999). It should be noted that an increasing number of pathogenic and potentially-pathogenic antibiotically stable microflora decreases the efficiency of such therapy for disbiotic disturbances. Because of this, their suppression will be more prospective, if we use metabolic probiotics and probiotic strains which produce bacteriocins and differ from antibiotics with more spare antimicrobial effect to normal microflora (Dunne et al., 1999).

Probiotic application based on bifidobacteria allows the achievement of the most expressive effects, both medical and prophylactic at the widest spectrum of diseases (Ouwehand et al., 2002).

Thus, present researches of bifidobacteria are vital because bifidobacteria and its metabolites are characterized by a number of advantages which are considered as the most prospective for probiotic basis of new generation. These bacteria are harmless for macroorganism, even at high concentration; it has antagonistic activity to a wide spectrum of pathogenic and potentially-pathogenic microorganisms; capable to render antiallergic and antitoxic effect, and stable at storage (Ouwehand et al., 2002).
$B$. bifidum, B. infantis, $B$. longum and $B$. adolescentis, $B$. breve play the most significant role in human gastrointestinal tract, therefore our researches were directed on the creation of a bifidobacterial consortium which has strong probiotic potential.

\section{MATERIALS AND METHODS}

\section{Antagonistic activity}

Antagonistic activity of Bifidobacteria was determined by the deferred antagonism method (Chervinec et al., 2006) in relation to clinical isolates of pathogenic and potentiallypathogenic microorganisms: selected from the intestines: Escherichia coli, Proteus mirabilis, Staphylococcus aureus, Salmonella typhimurium, Bacillus spp.; selected from vaginoses: $E$. coli, $S$. aureus; selected from urea: $E$. coli, P. mirabilis, S. aureus, were given by the National Scientific Medical Centre, Astana.

\section{Energy of acid production}

Energy of acid production was determined by the total quantity of organic acids by Turner's method (Egorov, 1995). Energy of acid production was determined by the quantity of organic acids, accumulated by bifidobacteria at the minimal infection of skim milk during $17 \mathrm{~h}$. A $0.1 \mathrm{~mL}$ of researched culture was seeded into $10 \mathrm{~mL}$ of milk. Tubes inoculated were incubated at $37^{\circ} \mathrm{C}$ for $17 \mathrm{~h}$. A $10 \mathrm{~mL}$ of test was diluted with $20 \mathrm{~mL}$ distilled water, and then 1 - 2 
drops of the phenolphthalein indicator was added. Titration was held at $0.1 \mathrm{~N} \mathrm{NaOH}$ until a steady pink colour emerged. The results were expressed in Turner degrees the following formula:

$\mathrm{K}=\mathrm{x} \times 10$.

$x$ - Quantity of $\mathrm{NaOH}$ in $\mathrm{mL}$, left on titration.

10 - Coefficient of transferring $\mathrm{ml}$ into Turner degrees.

Proteolytic activity is researched on the medium of Akman (Shamheva, 2003; Ananeva et al., 2007).

\section{Antibiotic sensitivity of Bifidobacteria}

Antibiotic sensitivity of Bifidobacteria was determined by the disc-diffusion method with the standard disks which were impregnated with 20 antibiotics (erythromycin, streptomycin, carbenicilin, cloramphenicol, tobramycin, kanamycin, neomycin, metronidazol, methicillin, cefamandol, cefazolin, gentamicin, ciprofloxacin, ofloxacin, amoxicillin, bacitracin, rifampicin, tetracycline, lincomycin and ampicillin) ("HiMedia", India) (Delgado et al., 2005). The strains with a certain clear zone indicates different resistance to the antibiotic whereby clear zones within; 0-5 $\mathrm{mm}$ were considered resistant; $6-10 \mathrm{~mm}$ were considered lowly-sensitive; 11-20 mm were considered sensitive and; more than $20 \mathrm{~mm}$ were considered highly-sensitive.

The quantity of vitamin $B_{12}$ was determined by Hamagaeva I.S. (Hamagaeva, 2006)

The culture medium was mixed with the cells carefully. For analysis, about $100-150 \mathrm{~mL}$ of the mixture is taken and centrifuged for $20 \mathrm{~min}$ at $6000 \mathrm{rpm} / \mathrm{min}$. Supernatant was removed, flushed with 3 to 4 volumes with distilled water, separating stripping water by centrifugation. Flushed biomass is weighed and transferred into Erlenmeyer's flask with 30-multiple amount of water and for preparation distilled water is acidized with $0.1 \mathrm{~N}$ of brine till 4.6 to $5.0 \mathrm{pH}$. Gained suspension is hydrolyzed in boiling water bath for $40 \mathrm{~min}$. After cooling, hydrolyzate is centrifuged, and the volume and $\mathrm{pH}$ are determined. It should be noted that the hydrolyzate should be acidized to a $\mathrm{pH}$ of 4.6-5.0 with $0.1 \mathrm{~N}$ of brine. The hydrolyzate is then placed under the lamp (60 W) for 30 min (in the case of precipitation, hydrolyzate is filtered through paper filter).

Absorbance of the solution is determined with the spectrophotometer at wavelength of $530 \mathrm{~nm}$ relative to the distilled water.

The contents of vitamin $B_{12}(\mu \mathrm{g} / \mathrm{mL})$ in the cultural medium is calculated with the following formula:

$\mathrm{C}=\mathrm{D}_{530} \cdot 10^{4} \mathrm{~V}_{1} / 56 \cdot \mathrm{V}_{2}$

where $C$ - the contents of $B_{12}, \mu \mathrm{g} / \mathrm{mL} ; D_{530}-$ absorbance of filtrate measured at $\lambda=530 \mathrm{~nm} ; V_{1}$ - volume of hydrolyzate, $\mathrm{mL} ; 56$ - a limiting factor for oxycobalamin under $\lambda=530 \mathrm{~nm} ; \mathrm{V}_{2}$ - amount of cultural medium taken for analysis, $\mathrm{mL}$.

To determine antimutagenic activity, Aims test was applied, whereby the strain S. typhimurium TA 1535 was used as the indicator of mutagenicity and 4-nitro-hinolin-1oxyd was used as the mutagen.

\section{Extraction of plasmid DNA was transacted by Boiling method (Holmes, 1981)}

A $1 \mathrm{~mL}$ of night culture was centrifuged at $6000 \mathrm{rpm} / \mathrm{min}$ for $5 \mathrm{~min}$. The supernatants were removed and the cell suspension was flushed several times with sterile distilled water. After adding $300 \mu \mathrm{L}$ of boiling buffer, mixing is done until the suspension becomes homogeneous. Lysozyme is added at a ratio of $1: 10(30 \mu \mathrm{L}$ on $300 \mu \mathrm{L})$. The cell suspension is boiled in the water bath for $40 \mathrm{~s}$ followed by centrifugation at $14,000 \mathrm{rpm} / \mathrm{min}$ for $12 \mathrm{~min}$ and the removal of cell precipitation. A $1 \mu \mathrm{L}$ of RNA-aza $(2.5 \mu \mathrm{g} / \mu \mathrm{L})$ is added to the solution and incubated at $37^{\circ} \mathrm{C}$ for $40 \mathrm{~min}$. $30 \%$ of PEG-6000 (in $180 \mathrm{uL}$ ) from the solution is added to precipitate the plasmids. The solution is incubated at 4 ${ }^{\circ} \mathrm{C}$ for $15 \mathrm{~min}$. Centrifugation was done at $14,000 \mathrm{rpm} / \mathrm{min}$ for $12 \mathrm{~min}$ and the supernatant is removed $70 \%$ ethanol is added to remove PEG - 6000 followed by mixing and centrifugation under $14,000 \mathrm{rpm} / \mathrm{min}$ for $12 \mathrm{~min}$. The ethanol is removed and the test tubes are dried at $37{ }^{\circ} \mathrm{C}$ for $10-15 \mathrm{~min}$. The precipitation is dissolved in $30 \mathrm{uL}$ of deionized water.

The boiling buffer: sucrose - 16, triton X-100 - $1 \mathrm{~mL}$, $20 \mathrm{~mL} 0.5 \mathrm{M}$ EDTA (pH 8.0), $2 \mathrm{~mL} 1 \mathrm{M}$ Tris $\mathrm{HCl}$.

\section{Lyophilized drying}

To create lyophilized bifidobacteria as dry microbial weight, bacterial suspension was stabilized by adding milksucrose medium (skim milk, $6 \%$ gelatin, $10 \%$ sucrose in the ratio $5: 1: 5)$ and was subjected to dry sublimation on lyophilized drying machine (model Vir Tis $4 \mathrm{~K}$, country of origin USA).

\section{RESULTS}

The determination of activity spectrum of each strain which is included in the consortium was very interesting and because of this antagonistic activity, each culture was studied. The results are presented in Table 1. Table 1 shows that all strains of Bifidobacteria, included in consortium, alongside with consortium itself present high level of antagonistic activity to pathogenic and potentiallypathogenic microflora (17 $\mathrm{mm}$ and more).

Moreover, a high level of antagonistic activity was shown for the consortium (growth inhibition zones of 20 $\mathrm{mm}$ and more).

\section{Studying vitamin forming abilities of Bifidobacteria}

Four selected cultures of Bifidobacteria were studied for vitamin forming ability, possessing most probiotical potential and consortium created on their base. The results are presented in Figure 1. Figure 1 provides information about cultures of Bifidobacteria which synthesize vitamin $B_{12}$. We have ascertained that bifidobacteria in the consortium contains $2.8 \mu \mathrm{g} / \mathrm{mL}$ to 5.2 $\mu \mathrm{g} / \mathrm{mL}$ of vitamin $B_{12}$. 
Table 1: An antagonistic activity of monocultured and consortium

\begin{tabular}{|c|c|c|c|c|c|c|c|c|c|c|}
\hline \multirow{2}{*}{ Names } & \multicolumn{10}{|c|}{ Growth inhibition zone, $\mathrm{mm}$} \\
\hline & 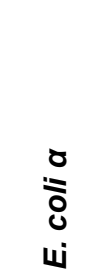 & 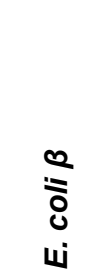 & $\begin{array}{l}\grave{\text { Oे }} \\
\text { نे }\end{array}$ & 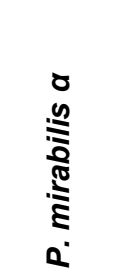 & 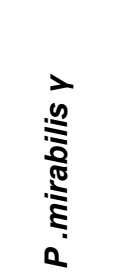 & 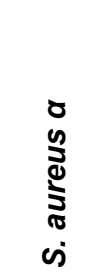 & 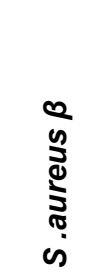 & 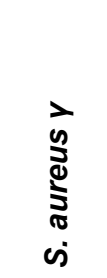 & 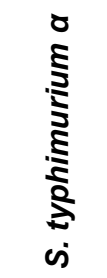 & 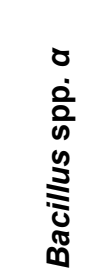 \\
\hline B. adolescentis 180 & $\begin{array}{l}17.2 \\
\pm 0.2\end{array}$ & $\begin{array}{l}33.5 \pm \\
0.5\end{array}$ & $\begin{array}{l}30.5 \pm \\
0.5\end{array}$ & $\begin{array}{l}22.2 \pm \\
0.7\end{array}$ & $\begin{array}{l}20.2 \pm \\
0.2\end{array}$ & $\begin{array}{l}18.7 \pm \\
0.4\end{array}$ & $\begin{array}{l}20.7 \pm \\
0.2\end{array}$ & $\begin{array}{l}26.5 \pm \\
0.5\end{array}$ & $\begin{array}{l}22.2 \pm \\
0.2\end{array}$ & $\begin{array}{l}28.5 \pm \\
0.6\end{array}$ \\
\hline B. breve 204 & $\begin{array}{l}18.0 \pm \\
0.4\end{array}$ & $\begin{array}{l}35.5 \pm \\
0.5\end{array}$ & $\begin{array}{l}30.0 \pm \\
0.4\end{array}$ & $\begin{array}{l}20.0 \pm \\
0.4\end{array}$ & $\begin{array}{l}22.5 \pm \\
0.3\end{array}$ & $\begin{array}{l}20.2 \pm \\
1.3\end{array}$ & $\begin{array}{l}20.5 \pm \\
0.5\end{array}$ & $\begin{array}{l}27,5 \pm \\
0.3\end{array}$ & $\begin{array}{l}22.7 \pm \\
0.4\end{array}$ & $\begin{array}{l}26.5 \pm \\
0.5\end{array}$ \\
\hline B. breve 584 & $\begin{array}{l}23.5 \pm \\
0.5\end{array}$ & $\begin{array}{l}33.0 \pm \\
0.9\end{array}$ & $\begin{array}{l}27.0 \pm \\
0.4\end{array}$ & $\begin{array}{l}22.2 \pm \\
0.6\end{array}$ & $\begin{array}{l}20.0 \pm \\
0.4\end{array}$ & $\begin{array}{l}17.0 \pm \\
0.7\end{array}$ & $\begin{array}{l}22.5 \pm \\
0.3\end{array}$ & $\begin{array}{l}25.7 \pm \\
0.2\end{array}$ & $\begin{array}{l}24.5 \pm \\
0.5\end{array}$ & $\begin{array}{l}28.7 \pm \\
0.4\end{array}$ \\
\hline B. breve 587 & $\begin{array}{l}17.2 \pm \\
0.6\end{array}$ & $\begin{array}{l}33.7 \pm \\
0.7\end{array}$ & $\begin{array}{l}30.0 \pm \\
0.5\end{array}$ & $\begin{array}{l}20.0 \pm \\
0.5\end{array}$ & $\begin{array}{l}20.2 \pm \\
0.2\end{array}$ & $\begin{array}{l}18.7 \pm \\
0.2\end{array}$ & $\begin{array}{l}20.0 \pm \\
0.5\end{array}$ & $\begin{array}{l}27.7 \pm \\
0.2\end{array}$ & $\begin{array}{l}25.7 . \pm \\
0.4\end{array}$ & $\begin{array}{l}25.5 \pm \\
0.6\end{array}$ \\
\hline Consortium & $\begin{array}{l}20.2 \pm \\
0.7^{* \star * *}\end{array}$ & $\begin{array}{l}34.0 \pm \\
0.5^{* *}\end{array}$ & $\begin{array}{l}30.2 \pm \\
0.4^{*}\end{array}$ & $\begin{array}{l}33.5 \pm \\
0.5^{* *}\end{array}$ & $\begin{array}{l}25.5 \pm \\
0.6^{*}\end{array}$ & $\begin{array}{l}23.2 \pm \\
0.4^{*}\end{array}$ & $\begin{array}{l}22.7 \pm \\
0.2^{*}\end{array}$ & $\begin{array}{l}28.2 \pm \\
0.2^{*}\end{array}$ & $\begin{array}{l}22.2 \pm \\
0.4^{*}\end{array}$ & $\begin{array}{l}27.5 \pm \\
0.5^{* \star}\end{array}$ \\
\hline
\end{tabular}

Note:

$\alpha$ - isolated at disbacteriosis; $\beta$ - isolated from vagina; $\gamma$ - isolated from urea.

${ }^{*}-p<0.01 ;{ }^{* *}-p<0.02 ;{ }^{* * *}-p<0.05$

Table 2: Biological activity of the consortium

\begin{tabular}{llll}
\hline Name & $\begin{array}{l}\text { Acid production } \\
\text { activity }\left({ }^{\circ} \mathrm{T}\right)\end{array}$ & Time of clot forming $(\mathrm{h})$ & $\begin{array}{l}\text { Proteolytic activity } \\
(\mathbf{m m})\end{array}$ \\
\hline Consortium & $146.2 \pm 0.2^{*}$ & $17.2 \pm 0.2^{* *}$ & $29.5 \pm 0.3^{*}$ \\
\hline${ }^{*}-p<0,01 ;{ }^{* *}-p<0,02$ & & &
\end{tabular}

Table 3: Antimutagenic activity of the consortium

\begin{tabular}{llll}
\hline Sample & Time cultivation (h) & $\begin{array}{l}\text { Average number of } \\
\text { revertants on a cup }\end{array}$ & Antimutagenic activity (\%) \\
\hline $\begin{array}{l}\text { Supernatant of cultural } \\
\text { liquid }\end{array}$ & 48 & 615 & 30.2 \\
Cells & 48 & 284 & 69.5 \\
\hline
\end{tabular}

\section{Biological activity of the consortium}

The results of biological activity of the consortium are presented in Table 2. As a result, high biological activity of the consortium was shown in both high acid production activity $\left(146^{\circ} \mathrm{T}\right)$ and high proteolytic activity $(29.5 \pm 0.3$ $\mathrm{mm})$. We have ascertained that the consortium is resistant to antibiotics such as erythromycin, streptomycin, carbenicilin, cloramphenicol, tobramycin, kanamycin, neomycin, metronidazol, methicillin, cefamandol, and cefazolin; lowly sensitive to gentamicin, ofloxacin and ciprofloxacin; sensitive to amoxycillin and bacitracin; highly sensitive to rifampicin, tetracycline, lincomycin and ampicillin.

\section{Studying antimutagenic activity of Bifidobacteria}

The results are presented in Table 3 . In contrast with the supernatant of cultural liquid, we noted that antimutagenic activity of cells of the consortium of bifidobacteria were expressed 2 to 3 times more.

Studying relationships of Bifidobacteria, commercial probiotical preparations and indigence Bifidobacteria during their combined cultivation

Combined cultivation of selected isolates of Bifidobacteria with probiotic strain B. bifidum 791 and the consortium has not ascertained antagonistic activity with each other. Studying bifidogenic effect of growth stimulation Ultrafiltrat (less than $10000 \mathrm{Da}$ ) of cultural medium B.breve 587 was added into the consortium as food substrate, concentrated and dried beforehand, whereupon bifidogenic effect of growth stimulation was registered. Figure 2 demonstrated the stimulation of the growth of the consortium, with is reflected in the lag phase in the first $3 \mathrm{~h}$. 


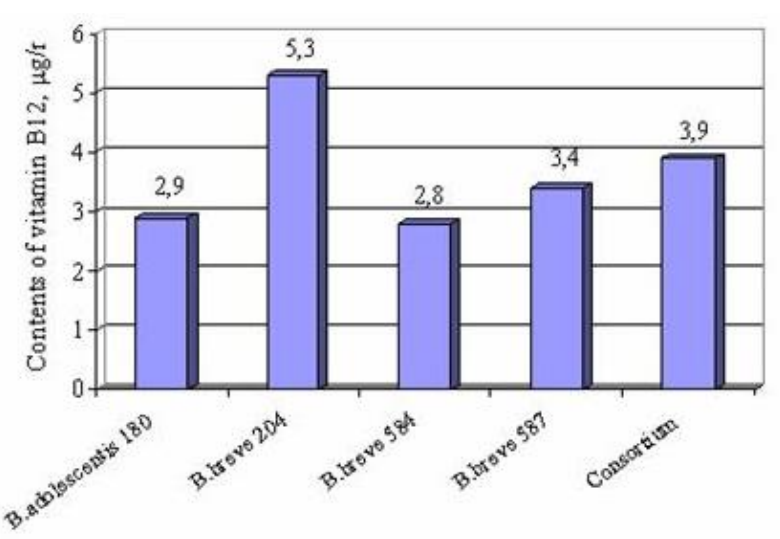

Figure 1: Product of monocultured consortium and consortium of the vitamin B12

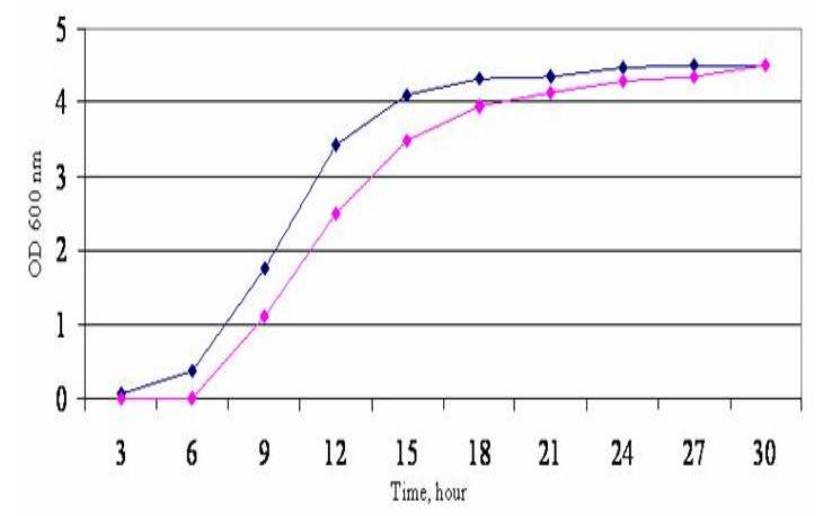

$$
\rightarrow \text { MRS +metabolit } \rightarrow \text { MRS }
$$

Figure 2: Growth dynamics of the consortium

\section{DISCUSSION}

Effective probiotics include several representatives of normal microflora of the intestine. As we mentioned before, Bifidobacteria has a dominant position. Because of this, 104 clinical strains of Bifidobacteria were studied. They were isolated from the adult population in different territorial zones of Kazakhstan, given by the National Scientific Medical Centre, Astana. 49 cultures of Bifidobacteria were identified. Hereinafter, the following probiotical characteristics were studied: antagonistic activity to pathogenic and potentially-pathogenic microflora, acid production activity, adhesive ability, proteolytic activities, and resistance to different concentrations of bile, gastric juice, phenols and sensitivity to antibiotics. The analysis of the results of these characteristics allowed selecting the following strains of Bifidobacteria: $B$. adolescentis 180, $B$. breve 204, B. breve 584 and $B$. breve 587 as microorganism, possessing high probiotical potential and technological characteristics, at the expense of the first antimicrobial metabolites (the organic acids and proteolytic enzymes) and bacteriocin production in the last.
Furthermore, we have ascertained a correlation between the antagonistic activity of the strain $B$. adolescentis 180 and its organic acid production, in other words, given strain possesses high antagonistic and high acid production activity, as well as between its antagonistic and proteolytic activity.

Also, correlation relationships between antagonistic activity of the strains $B$. breve 204 and $B$. breve 584 with proteolytic activity (the high antagonistic activity and high proteolytic activity) were ascertained. It should be noted that the interest on the strain $B$. adolescentis 180 was due to the probiotical culture and possibility to use it with antibiotic of broad functioning spectrum because it is resistant to 9 from 10 researched antibiotics (erythromycin, streptomycin, gentamicin, carbenicilin, cloramphenicol, tobramycin, kanamycin, tetracycline, ampicillin).

Whereas, isolate $B$. breve 584 alongside with strong probiotical properties possesses such useful technological factors as reduction of methylene blue in 4 $\mathrm{h}$ and milk clotting in $17 \mathrm{~h}$.

Because of the creation of multicomponent probiotics, biotechnologists face a number of problems in all stages of the technological processes, starting from the first stage of the strain selection. Alongside with generally accepted criteria of selection strains-pretenders must be compatible with biological characteristic i.e. must not suppress each other under combined cultivation (Dorofeeva, 2007).

Therefore, initial stages of the work were connected with studying interspecific antagonism of Bifidobacteria. As a result, none of them suppress the growth of another pretender to probiotics.

Afore-mentioned strains were joined in consortium in order to get a Bifidobacter which has collection of characteristics of all its components to increase probiotical effect.

It is generally known that probiotics are identified as living microorganisms, which being entered into organism in composition of preparations, beneficially influence human's or animal's health. A significant part of the work in this area, first of all is directed to the correction of disbiotical injures in the gastrointestinal tract. We studied antagonistic activity of the consortium on the base of Bifidobacteria related to the pathogenic and potentiallypathogenic microflora, chosen during disbacteriosis, and causing microecological shifts in vagina and urea.

Thereby, constructed consortium is directed to the correction of disbacteriosis of different biotops. Studying antagonistic activity of monostrains of consortium showed that the most sensitive was potentiallypathogenic microflora of both vagina and urea, so, for $E$. coli and $S$. aureus, selected from the given biotops showed the strongest antagonistic activity [the average zones of growth inhibition are $34 \mathrm{~mm}$ (obtained from vagina) and $29 \mathrm{~mm}$ (obtained from urea) for E. coli; 21 $\mathrm{mm}$ (obtained from vagina) and $27 \mathrm{~mm}$ (obtained from urea) for $S$. aureus]. In contrast with activity shown to mentioned microorganisms, but isolated at disbacteriosis 
(by $19 \mathrm{~mm}$ respectively). Then, in relation to $P$. mirabilis such dependencies is not Bifidobacter.

Studying antagonistic activity of the consortium showed that the most sensitive culture is $E$. coli isolated from vagina and urea, as well as $P$. mirabilis, chosen at disbacteriosis. Also, for bifidobacterial strains which are included in the consortium, discharge place dependence of activity was ascertained, for instance, E. coli, insulated from vagina and urea showed strong antagonistic activity, than for E. coli, isolated during disbacteriosis, in ditto time strong activity was shown by $S$. aureus, chosen only from urea, in contrast with $S$. aureus, insulated from the other places.

Thereby, antagonistic activity of the consortium, in comparison with activity of monocultures is more expressed, monocultures of Bifidobacteria show less activity, particularly to $P$. mirabilis and $S$. aureus.

Bifidobacteria produce considerable amount of vitamin $B_{12}$ in active coferment form. It is known that $B_{12}$ promotes increasing immunity status of the organism, influences blood formation by activating blood clotting process, takes part in syntheses of different amino acids, and activates the processes of fats and carbohydrate exchange. It also has good effect on liver functions, nervous and digestive systems.

Consortium showed produce $>5.2 \mu \mathrm{g} / \mathrm{mL}$ vitamin $B_{12}$, since $B$. breve 204 clone produce $5.2 \mu \mathrm{g} / \mathrm{mL}$. As mentioned above, strains which are included in the consortium have to increase their biological activity. Therefore, we examined the most important probiotical and technological characteristic of the consortium: acid production, proteolytic activities, as well as time determination of clotting by consortium.

As a result, we ascertained the rise of acid production activity of the consortium (up to $146{ }^{\circ} \mathrm{T}$ ), whereas maximum acid production activity was noted only in the strain $B$. adolescentis $180\left(124^{\circ} \mathrm{T}\right)$, which enters into the composition of consortium.

The time of the consortium clotting amounts to $17 \mathrm{~h}$ that is supposedly connected with vital activity of the strain $B$. breve 584 , since given index corresponds to its average index of time clotting. Proteolytic activity of the consortium forms $30 \mathrm{~mm}$ and $21 \mathrm{~mm}$ respectively. Note that suppressions or reinforcement does not occur.

Thereby, after combining selected cultures of bifidobacteria in the consortium, proteolytical and lipolytical characteristics are seen on the background of increasing acid production activity and reduction of time clotting.

The profile of antibiotic sensitivity of the consortium was studied with the following antibiotics: rifampicin, erythromycin, streptomycin, gentamicin, carbenicilin, cloramphenicol, tobramycin, kanamycin, tetracycline, neomycin, metronidazol, methicillin, cefamandol, ciprofloxacin, lincomycin, bacitracin, cefazolin, ofloxacin and ampicillin.

As a result, we ascertained that the consortium is resistant to 11 from the 20 studied antibiotics; this shows its strong antibiotic resistance comparing with antibiotic resistance of monostrain in its composition.
Note that one of the important criteria of probiotics is plasmid absence, which, as is well known, can have the antibiotic resistance factors, which can provide the receptive types of pathogenic and potentially-pathogenic microflora resistance to antibiotics (Glushanova, 2005). Because of this, all monostrains of the consortium were studied on plasmid presence. None of them is their carrier.

It is well known that bacteria, evolutionary to the most ancient essences, are constantly subjected to mutagenic and inactivating factors of the environment. That is supposed to be that bacteria must possess the reliable protective characteristics for conservation stability of its genome, except reparation system of DNA, they could work out protection by synthesizing material with protective, reactivating and antimutagenic characteristics.

Studying antimutagenes is important, first of all, in relation to bacteria which are used as probiotics.

As a result, we ascertained that supernatant of cultural liquid and cells of the consortium of Bifidobacteria possess antimutagenic activity in respect to 4nitrohinolin-1-oxides. This is connected to the fact Bifidobacteria synthesize the antioxidants enzymes such as superoxiddismutasa and others. The presence of these enzymes allows the cell to remove superoxide radicals, formed in oxidation reaction.

Thereby, it was observed that Bifidobacteria are capable to junction biosyntheses which possess protective action from external and endogenous mutagens.

Nowadays, main conservation and correction means of normal flora remain the Bifidobacteria preparations on the base of high antagonistic strain of Bifidobacterium spp. And of Lactobacterium spp., applicable peroraly, intrarectally and/or intravaginally as apart, so in combinations with each other (Salminen, 2001).

Because of this, relationship evaluation of Bifidobacteria which is included in commercial probiotical preparation, and human's indigents bifidobacteria at their combined cultivation is very interesting.

As a result, no antagonistic activity between them was ascertained, consequently, combining usage is possible.

As mentioned before, the most effective way to normalize intestine imbalance is to use probiotics. Note that probiotical effect increases at simultaneous using of probiotics, meanwhile implanting entered microorganisms and stimulating own microflora.

Importance of such preparations is really topical, since unfavourable ecological situation, the work in bad physical conditions, chemical and other influence, insufficient or unbalanced feeding, finally brings about origin of intestine disbacteriosis.

Nowadays perspective acceptance in creation of such preparations is searching for and introduction in production substance of natural origin, possessing both technological and physiological functionality. Such products of metabolism are secreted into cultural medium and presenting itself with collection of the valuable 
nutrients together with milk and acetic acid. They selectively stimulate growth and development of micro flora of intestine (Bifidobacteirium spp. and Lactobacterium spp.) (Kiselev, 2007).

Growth stimulation of the consortium is shown by expressing in lag phase reduction for $3 \mathrm{~h}$ in contrast with initial growth of the consortium and earlier entering of the consortium into stationary phase. In other words, the growth stimulations of the Bifidobacteria in the consortium was observed, it will help to shorten both time for Bifidobacteria adaptation and acceleration of the consortium growth. The given example shows the possibility of probiotical mechanism under cultivation of consortium.

Thereby, constructed consortium possesses more expressed probiotical effect. So, consortium has high antimicrobial activity to pathogenic and potentiallypathogenic microflora, insulated during disbacteriosis, as well as from vagina and urea. Consequently, it is possible to use the consortium during infectious disease of gastrointestinal tract, female sexual sphere and urogenital tract. The output of the vitamin takes role in amino acid syntheses, nucleic acids, in the process of the carbohydrate and fat exchange, together with proteolytic activity promote the beneficial influence on Bifidobacteria as a whole and on gastrointestinal tract, in particular. Besides, antimutagenic effect of the consortium serves as the barrier from external and endogen mutagens. The stability of the consortium to majority of studied antibiotics is that it gives evidence about the possibility of combining usage with them. Note that the absence of the antagonistic activity between consortium and commercial Bifidobacteria preparation makes their combinative usage possible. Note that prebiotical effect on the consortium is given by ultrafiltrat of cultural medium B. breve 587 . Therefore, consortium made on the base of Bifidobacteria strains of Bifidobacteria could be recommended as preparation for treatment and preventing infections of gastrointestinal tract, female sexual sphere and urogenital tract.

In order to stabilize bifidobacterial cultures in the bifidobact production, lyophilized drying is used in the application of sucrose-gelatin-milk protective medium which is used in majority production of probiotical preparation. The consortium in lyophilized drying condition was received with residual moisture of $2.5 \%$.

As a result, bifidobacterial consortium was received, possessing the following advantages: contains microbial mass of living, antagonistically active Bifidobacteria strains $B$. breve and $B$. adolescentis; contains more than $10^{9}$ alive Bifidobacteria; does not contain plasmids, which means that it could not be a carrier of antibiotic stability to Gram-positive receptive pathogenic and potentiallypathogenic microflora.

\section{REFERENCES}

Ananeva, N. V. and Ganina, V. I. (2007). The influence of the exsopolycarbogidrats on the stress stability of probiotical culture. Materials from the international congress "Probiotics, prebiotics, synbiotics and functional nutrition products. Fundamental and clinical aspects - St-Petersburg 1, 20-21.

Chervinec, I. V., Bondarenco, V. M., Shabanova, H. A., Samoukina, A. M. and Chervinec, V. N. (2006). Bacteriocinogenic high antagonistic strains of lactobacillus. 7, 79-81.

Delgado, S., Florez, A. B. and Mayo, B. (2005). Antibiotic susceptibility of Lactobacillus and Bifidobacterium species from the human gastrointestinal tract. Current Microbiology 50, 202205.

Dorofeeva, E. S., Blinkova, L. P., Mashenceva, N. G., Lapteva, I. A. and Baranova, E. A. (2007). Bacteriocin-like compounds and gene site which control their synthesis in new candidates to probiotics. Materials from the international congress "Probiotics, prebiotics, synbiotics and functional nutrition products. Fundamental and clinical aspects - St-Petersburg 1, 38-41.

Dunne C., Murphy L., Flynn S., O'Mahony L., O'Halloran S., Feeney, M., Morrissey D., Thornton G., Fitzgerald G., Daly C., Kiely B., Quigley E. M. M., O'Sullivan G. C., Shanahan F. and Collins K. J. (1999). Probiotics: From myth to reality. Demonstration of functionality in animal models of disease and in human clinical trials. Kluwer Academic Publishers 76, 279-292.

Egorov, N. S. (1995). Manual to practical microbiology. MSU. 186-191.

Glushanova, N. A. and Shenderov, B. A. (2005). The relationships of probiotical and indigent Lactobacillus of the master in combinative cultivation conditions in vitro. Journal of Microbiology 2, 56-65.

Hamagaeva, I. S., Kachanina, L. M. and Tumurova, S.M. (2006). Biotechnology of the propionic acid bacterial leavens. Publishers VSSTU. 149-153.

Holmes, D. S. and Quigley, M. (1981). A rapid boiling method for the preparation of bacterial plasmids. Analytical Biochemistry 114, 193-194.

Kiselev, S. A. and Chicherin, D. S. (2007).Probiotics: the new approach to mechanism of the therapeutic action at treatment disbacteriosis of intestine. Materials from International congress "Probiotics, prebiotics, synbiotics and functional nutrition products. Fundamental and clinical aspects - StPetersburg, 1, 44-51.

Ouwehand, A. C., Salminen, S. and Isolauri, E. (2002). Probiotics: An overview of beneficial effects. Antonie Van Leeuwenhoek 82, 279-289.

Shamheva, E. B. (2003). Sdady of proteolytic activity bifidobacterias. Material to scientific conference student and graduate student TSU. 83-91.

Salminen S. (2001). Human studies on probiotics: Aspects of scientific documentation. Scandinavian Journal of Nutrition 45, 8-14. 